\title{
Cervical Undifferentiated Carcinoma
}

National Cancer Institute

\section{Source}

National Cancer Institute. Cervical Undifferentiated Carcinoma. NCI Thesaurus. Code C6345.

A carcinoma that arises from the cervix and is characterized by the lack of specific cellular differentiation. 